\title{
Effects of Package Matenials on Quality Change of Pine Bud Beverage Under Ultraviolet Light
}

\author{
Duek-Jun An \\ Department of Food Science, SunMoon University, Chungnam 336-840, Korea
}

\begin{abstract}
The effects of packaging materials on preserving the functional component of pine bud beverage stored under UV (ultraviolet) light exposure conditions were studied. The order of UV light blocking properties of the selected packages was: opaque can $>$ opaque PET (polyethylene terepthalate) with green lamination=transparent PET with 10\% PEN (polyethylene naphthalate) blending > transparent PET, and did not depend on film thickness in specified range. At $20^{\circ} \mathrm{C}$, the order of preserving degree of original color and endobomyl acetate, which is quality index of pine bud beverage, was the same as above. Exposure to UV light can cause of deterioration of functional food components, but green color lamination and blending of PEN materials with transparent PET help to preserve the UV sensitive pine bud beverage components. However, the treated PET bottles have poorer preservation capabilities than the opaque cans. Transparent PET with PEN blending, in particular, will be very useful packaging material for colorful functional beverage preservation by helping to protect the ingredients while attracting consumer attention.
\end{abstract}

Key words: pine bud beverage, PEN (polyethylene naphthalate), UV (ultraviolet) light, PET (polyethylene terepthalate), green lamination

\section{INTRODUCTION}

From commercial standpoint, functional food can be a very attractive item in societies in which consumers are health- and beauty-oriented. However, many functional components and colorants that have several double bonds in their structure are subject to loss of their original functionality, including color change, due to exposure to light. This is especially true for ultraviolet light, which can cause disrupture or dislocation of double bonds by photo degradation $(1,2)$. Chan (2) mentioned that even though the double bonds in functional components are not normally subjected to direct ultraviolet irradiation, they can undergo photo-sensitized oxidation owing to light absorption. This can eventually cause quality changes in the product, including flavor and color losses. Additionally, Kim and Park (3) reported toxic photo products were generated by the light $(290 \mathrm{~nm} \sim 700 \mathrm{~nm})$ exposure to some medicines, which resulted in toxic or carcinogenic materials. Therefore, foods and pharmaceutical solutions that are sensitive to light should be protected from ultraviolet light by adoption and designing of suitable packaging materials $(4,5)$.

Metal or aluminum has been used as packaging material in the form of can, which is designed to protect the contained functional component from UV light and me- chanical damage. In recent years, plastic bottles with coloring laminated or blended materials have been used for better preservation of functional beverage and for diversification of the packaging unit; however, the colored bottle, whose effect on preservation of functional component is not as well known, is not friendly to environment. Therefore, several ultraviolet absorbing or blocking agents were developed for protection of functional beverages bottled in transparent plastic. However, data are still sparse on the relations of various packaging materials to the degradation of functional components and properties under ultraviolet light, so more thorough and detailed research are needed. For example, endobornyl acetate from pine bud gives the smell and color of pine needles, so it is a very attractive functional component for beverages (6). However, it is very difficult to preserve during its storage time due to its sensitivity to ultraviolet light.

While the metal can is very effective for protecting endobornyl acetate, it is not possible for consumer to enjoy the color of pine bud beverage. Our objectives were to determine the effect of various packaging materials on degradation of functional components in pine bud beverage under ultraviolet light and also to find transparent packaging material with ultraviolet absorbing

E-mail: djan@sunmoon.ac.kr

Phone: +82-41-530-2287, Fax: +82-41-530-2917 
capacity.

\section{MATERIALS AND METHODS}

We tested four materials (metal, transparent PET, opaque PET with green lamination, transparent PET with PEN) representing different thicknesses and activation spectra maximums. Color change was monitored by chromameter and volatile functional component was entrapped by nitrogen purge and trap method at $70^{\circ} \mathrm{C}$, and gas chromatography (G.C.) - Mass spectrometer (M.S.) was used to observe change of functional component compositions and identify the chemical structures of them.

\section{Pine bud beverage}

Pine bud beverage containing $500 \mathrm{mg}$ pine bud extract, which is packed in metal can $(240 \mathrm{~mL})$, was obtained from a local food company and were stored at room temperature.

\section{Packages}

Packages for storing the pine bud beverage were metal cans $(52.5 \mathrm{~mm} \times 133.1 \mathrm{~mm}$ ), and bottles of PET (polyethylene terephthalate), PET with green lamination, and PET with $10 \%(\mathrm{w} / \mathrm{w})$ polyethylene naphthalate $(\mathrm{PEN})$. $(65.4 \mathrm{~mm} \times 206.5 \mathrm{~mm})$ The resin is capable of withstanding high temperature conditions and is also known to be a better ultraviolet light barrier with high transparency than PET (7). Unused, clean, blow-molded PET, PET with green lamination, and PET with PEN were obtained from a local company.

\section{Storage for UV light exposure}

Ultraviolet light TLD 18 W/0 8 (Philips Co.) for UV light was purchased from local company and Sanyo pharmaceutical chamber was used in closed condition for storage of each packaged beverage at $20^{\circ} \mathrm{C}$.

\section{Measurement of physical properties of packaging materials}

Thickness: A coating thickness meter, UNO-CHECK 'FE' from List-Magnetik Co., was used to measure thickness of each test specimen at room temperature three times.

Light Absorption Spectrum and \% Transmission: UV/ Visible spectrophotometer (Perkin-Elmer Lamba 4B, USA) was used to measure light absorption/transmission spectrum $(190 \mathrm{~nm} \sim 380 \mathrm{~nm})$ of each plastic film, which was cut into $3 \mathrm{~cm} \times 5 \mathrm{~cm}$. To measure $\%$ transmission of each plastic film, UVI ultraviolet transilluminators were used at 3 ultraviolet wavelengths: 254, 312, 363 nm.

\section{Sampling of pine bud beverage}

Pine bud beverage in steel cans were transferred to the PET, PET with lamination and PET with PEN up to highest level of each bottle in clean bench. After capping each bottle, they were sterilized in hot water $\left(85^{\circ} \mathrm{C}\right)$ for $30 \mathrm{sec}$ in a cooker-mixer and stored in pharmaceutical stability chamber with UV light at $20^{\circ} \mathrm{C}$. Each bottle was about $45 \mathrm{~cm}$ from the Ultraviolet light TLD.

Color change of pine bud beverage by UV inadiation

Chroma meter JS555 with accessories was used to measure color change during UV light exposed condition in every three days. The Hunter system was employed to show the color change as L (brightness), a (hue, degree of redness), and $b$ (chroma, degree of yellowness) value.

\section{UV imadiation of flavor profile pine bud extract}

Pine bud extract was obtained from a local food company and tightly wrapped in aluminum foil and stored in a refrigerator at $4^{\circ} \mathrm{C}$. The pine bud extract $(0.1 \mathrm{~g})$ was diluted in $5 \mathrm{~mL}$ of water, by shaking vigorously for $3 \mathrm{~min}$, and stored in 10 separate clear glass bottles. Half of these bottles were irradiated with UV light while the other five bottles were wrapped with aluminum foil to avoid the light illumination and were allowed to stand at $20^{\circ} \mathrm{C}$ for the same period of time. Changes in the flavor profile were determined by G.C. (8-10) by comparing calibration chart vs distilled pine bud extract of $\mathrm{GC}$ areas.

\section{Isolation and detemination of change of volatile} flavor

Flavor change was determined in a Dynamic Thermal Stripper (Dynamic Co., USA) system by the NPT (nitrogen purge and trap) method. After storing each bottle for one day at room temperature, $20 \mathrm{~mL}$ strip vials with individual pine bud beverage samples weighed $( \pm$ $1 \mathrm{mg}$ ) were prepared and heated at $70^{\circ} \mathrm{C}$ for $3 \mathrm{~min}$ in DTS system. The volatile flavors were driven into Tenax-TA $(15 \mathrm{~cm} \times 4 \mathrm{~mm} \mathrm{ID}$, Supelco Co. $)$ by nitrogen gas $(220 \mathrm{~mL} / \mathrm{min})$. The entrapped flavors were released by Thermal Desorption Unit (Dynamic Co.) and injected into gas chromatography through a stainless steel pipe. A Hewlett Packard 5890 Gas chromatography with flame ionization detector and SE-54 fused silica capillary column $(0.32 \mathrm{~mm} \times 60 \mathrm{~m})$ from Supelco Co. were used. Additional operation conditions included $\mathrm{He}$ gas at 1 $\mathrm{mL} / \mathrm{min}$. and injection port $220^{\circ} \mathrm{C}$ and detector $265^{\circ} \mathrm{C}$. Column temperature was programmed from $35^{\circ} \mathrm{C}$ to $250^{\circ} \mathrm{C}$ at $8^{\circ} \mathrm{C} / \mathrm{min}$. A Hewlett Packard 3365 ChemStation program was used to analyse and integrate the obtained peak. 
Table 1. Effects of film thickness of packages on \% transmission of UV light at $363 \mathrm{~nm}$

\begin{tabular}{lcc}
\hline Packaging materials & $\begin{array}{c}\text { Thickness } \\
(\mu \mathrm{m})\end{array}$ & $\begin{array}{c}\% \text { transmission } \\
\text { of UV }(\%)\end{array}$ \\
\hline \multirow{2}{*}{ PET } & 359 & 78 \\
& 469 & 76 \\
& 554 & 79 \\
\multirow{2}{*}{ PET with green lamination } & 492 & 3 \\
& 578 & 3 \\
& 740 & 4 \\
\multirow{2}{*}{ PET with PEN } & 388 & 3 \\
& 477 & 3 \\
& 593 & 2 \\
\hline
\end{tabular}

\section{Identification of pine bud flavor component}

Analysis was carried out using a Hewlett Packard 5890 Gas chromatography with same condition as that of analysis of flavor change and a mass selective detector VG Platform II with a potential of $70 \mathrm{eV}$ for ionization by electron impact. The identification was done by comparing both the sample compound's retention index and mass spectrum data with the retention index data bank in International Flavors and Fragrances and the mass spectra library, obtained using the authentic compounds (11-13).

\section{RESULTS AND DISCUSSIONS}

\section{Physical properties of various packaging materials}

Thickness: The effect of thickness and density of each packaging materials on UV blocking property were studied. As seen in Table 1, UV light blocking property did not depend on thickness of each plastic film in the specified range $(359 \mu \mathrm{m} \sim 740 \mu \mathrm{m})$.

Light absorption spectrum and \% transmission: The spectrum of each film in ultraviolet range $(190 \mathrm{~nm} \sim 380$ $\mathrm{nm})$ was investigated. The activation spectra maxims for both PET with PEN and green lamination were $380 \mathrm{~nm}$, but transparent PET has $325 \mathrm{~nm}$ of spectra maxims.
Table 2. \% transmission of selected package materials in three UV light range

$(\%)$

\begin{tabular}{ccccc}
\hline Wavelength & PET & $\begin{array}{c}\text { PET with green } \\
\text { lamination }\end{array}$ & $\begin{array}{c}\text { PET with } \\
\text { PEN blending }\end{array}$ & Can \\
\hline $254 \mathrm{~nm}$ & 2 & 3 & 5 & 0 \\
$312 \mathrm{~nm}$ & 5 & 4 & 5 & 0 \\
$363 \mathrm{~nm}$ & 77 & 3 & 2 & 0 \\
\hline
\end{tabular}

This means PET with PEN green lamination block transmission of UV light below wavelengths of $380 \mathrm{~nm}$, while transparent PET does allow the transmission of UV light up to $325 \mathrm{~nm}$. Therefore, PET with PEN and green lamination are better UV light. barriers than clear PET. A \% transmission of each film was shown in Table 2. From these data, we assume that NDC (Naphthalene Dicarboxylate monomer) and green lamination act as a UV blocking agents and can protect UV light sensitive food ingredients.

\section{Monitoring of color change}

According to the data of color change in pine bud beverage stored in the various packaging materials, PET with green lamination resulted in the least color difference as compared to the aluminum steel stored pine beverage (Table 3). In redness (a), the order of preserving degree of original color under ultraviolet condition was: Can $>$ PET with green lamination $>$ PET with PEN $>$ PET, which was the order of decreasing \% transmission rate of ultraviolet. Degree of color change based on yellowness was same order as that of redness. Results indicate that $\%$ transmission rate of package materials under UV exposed condition affect color change of light sensitive component in the contained food.

\section{Identification of pine bud extract flavor}

The identified pine bud flavor compounds with GC-MS were listed in Table 4. Among them, alphapinene (RT. $12.58 \mathrm{~min}$ ), beta-pinene (RT. $13.63 \mathrm{~min}$ ), alpha-fenchene (RT. $14.82 \mathrm{~min}$ ) and endobornyl acetate (RT. $20.49 \mathrm{~min}$ ) were considered as major flavor com-

Table 3. Color change of each packaged pine bud beverages in UV light exposed condition

\begin{tabular}{|c|c|c|c|c|c|c|c|c|c|c|c|c|}
\hline \multirow{2}{*}{ Packaging materials } & \multicolumn{4}{|c|}{1 week } & \multicolumn{4}{|c|}{2 weeks } & \multicolumn{4}{|c|}{3 weeks } \\
\hline & \multicolumn{3}{|c|}{$\mathrm{b}$} & $\mathrm{L}$ & $\mathrm{a}$ & \multicolumn{2}{|c|}{$\mathrm{b}$} & L & $\mathrm{a}$ & \multicolumn{2}{|c|}{$\mathrm{b}$} & $\mathrm{L}$ \\
\hline PET & -1.23 & \multicolumn{2}{|c|}{4.23} & 97.49 & -1.15 & \multicolumn{2}{|c|}{4.20} & 8.06 & -1.10 & \multicolumn{2}{|c|}{3.55} & 98.42 \\
\hline PET with green & -1.57 & \multicolumn{2}{|c|}{4.58} & 96.87 & -1.54 & \multicolumn{2}{|c|}{4.40} & 6.82 & -1.53 & \multicolumn{2}{|c|}{4.23} & 97.03 \\
\hline PET with PEN & -1.61 & \multicolumn{2}{|c|}{4.53} & 96.90 & -1.59 & \multicolumn{2}{|c|}{4.46} & 6.88 & -1.60 & \multicolumn{2}{|c|}{4.31} & 97.28 \\
\hline Can & -1.56 & & & 96.23 & -1.60 & 4.55 & \multicolumn{2}{|c|}{96.56} & -1.57 & 4.5 & & 96.22 \\
\hline \multirow{2}{*}{ Packaging materials } & \multicolumn{3}{|c|}{4 weeks } & \multicolumn{3}{|c|}{5 weeks } & \multicolumn{3}{|c|}{6 weeks } & \multicolumn{3}{|c|}{7 weeks } \\
\hline & $\mathrm{a}$ & $\mathrm{b}$ & $\mathrm{L}$ & $\mathrm{a}$ & $\mathrm{b}$ & $\mathrm{L}$ & $\mathrm{a}$ & $\mathrm{b}$ & $\mathrm{L}$ & $\mathrm{a}$ & $\mathrm{b}$ & $\mathrm{L}$ \\
\hline PET & -1.00 & 3.13 & 99.12 & -0.89 & 3.07 & 99.13 & -0.92 & 2.97 & 99.28 & -0.91 & 2.96 & 99.21 \\
\hline PET with green & -1.52 & 4.06 & 97.34 & -1.49 & 3.83 & 98.03 & -1.52 & 3.74 & 97.99 & -1.50 & 3.81 & 98.84 \\
\hline PET with PEN & -1.55 & 4.33 & 97.13 & -1.57 & 4.01 & 97.29 & -1.53 & 4.11 & 97.76 & -1.52 & 3.98 & 98.17 \\
\hline Can & -1.54 & 4.52 & 96.39 & -1.58 & 4.20 & 96.35 & -1.56 & 4.33 & 96.60 & -1.56 & 4.23 & 96.23 \\
\hline
\end{tabular}


pounds by $\%$ order of individual peak area in total peak and their properties. According to previous research (14-18), endobornyl acetate smells of pine needles and is considered to be the main flavor quality index of pine bud extract due to its high sensitivity against external condition. Endobornyl acetate imparts a refreshing, fresh taste and piney odor. Alpha and beta pinenes have characteristic odor of pine and turpentine-like odor, but they seem to be lost during production of pine bud beverage. In addition, alpha-fenchene (camphene) used for reduction of the cholesterol saturation index in the treatment of gallstones and also has burning odor and taste, and gives yellowish color.

\section{UV inadiation of pine bud beverage}

To verify UV irradiation of pine bud beverage and determine main peak of pine bud beverage, flavor profile of the beverage with clear glass was compared with that of the beverage with aluminum foiled glass under UV light exposure. Because clear glass provides a perfect barrier against outer gases and moisture except transmission of light, it was selected to investigate the effect of UV light only on the stability of functional components in pine bud beverage. Alpha-fenchene and endobornyl acetate were present in the beverage as major flavor components. Table 5 showed UV light deteriorated the flavor profile of pine bud beverage with clear glass,

Table 4. Peak of pine bud extract and its identification

\begin{tabular}{ccl}
\hline Peak \# & Retention time (RT) & Identified compound \\
\hline 1 & $12.58 \mathrm{~min}$ & Alpha-pinene \\
2 & $13.63 \mathrm{~min}$ & Beta-pinene \\
3 & $14.82 \mathrm{~min}$ & Alpha-fenchene \\
4 & $16.14 \mathrm{~min}$ & Gamma-terpinene \\
5 & $17.19 \mathrm{~min}$ & Camphor \\
6 & $20.49 \mathrm{~min}$ & Endobornyl acetate \\
\hline
\end{tabular}

Table 5. Effect of UV light on fractional composition of major flavor components of pine bud beverage

\begin{tabular}{lccc}
\hline \multirow{2}{*}{ Peak } & At & \multicolumn{2}{c}{ After 7 weeks under UV light } \\
\cline { 3 - 4 } & initial & $\begin{array}{c}\text { Aluminum } \\
\text { wrapped glass }\end{array}$ & $\begin{array}{c}\text { Transparent } \\
\text { glass }\end{array}$ \\
\hline Alpha-fenchene & 54.6 & 55.3 & 77.1 \\
Camphor & 3.9 & 4.8 & 12.1 \\
Endobornyl acetate & 28.1 & 25.4 & 3.1 \\
\hline
\end{tabular}

while aluminum wrapped glass prevents quality change of pine bud beverage from UV light exposure. From these data, it was concluded that endobornyl acetate was very sensitive to UV light and \% decreased and increased proportion of endobornyl acetate and alpha-fenchene respectively could be a main quality index of pine bud beverage under the UV light exposed condition. Increased yellowness of pine bud beverage with UV light exposure may be the results of increased proportion of alpha-fenchene.

\section{Flavor change with various packaging materials}

Change of flavor profile in the various packaged pine bud extract beverages under UV light exposure conditions at $20^{\circ} \mathrm{C}$ was examined. The $\%$ decrease of endobornyl acetate, and increase of alpha-fenchene and camphor in the beverage were shown in Table 6. Order of $\%$ proportion of endobornyl acetate in each packaged beverage was opaque can $>$ opaque green PET=transparent PET with PEN $>$ transparent PET, which was in accord with the order of decreasing \% transmission of ultraviolet light at $363 \mathrm{~nm}$. These results indicate that stability of endobornyl acetate, which is a quality index of pine bud beverage, was strongly affected by UV light Green color lamination and blending of PEN material to clear PET bottles also preserve the UV light sensitive components and their combination has additional preservation effects on the light sensitive functional components.

UV light blocking properties can be improved with green lamination and blending of PEN materials to PET. Retention of endobornyl acetate, which is the major quality index flavor in pine bud beverage, was remarkably increased with the use of appropriate packaging materials under UV light exposed condition. These results imply that selection and evaluation of packaging materials for extending shelf life are very important processes in developing of new functional food items.

Moreover, transparent plastic packaging material is more reusable compared to laminated, opaque plastic packaging. Thus, knowledge of the transparent packaging materials with UV light barrier properties for extending shelf life can also provide guidance regarding which such recycle packaging materials to use.

Table 6. Change of flavor profile in the various packaged pine bud beverage under UV light exposed condition at $20^{\circ} \mathrm{C}$

\begin{tabular}{lccccccc}
\hline Packaging materials & 1 week $^{1)}$ & 2 weeks & 3 weeks & 4 weeks & 5 weeks & 6 weeks & 7 weeks \\
\hline \hline PET & $61.5: 4.1: 25.0$ & $60.3: 3.7: 23.1$ & $66.7: 4.0: 22.9$ & $68.9: 3.8: 19.5$ & $72.4: 3.6: 15.8$ & $75.4: 3.9: 14.6$ & $76.1: 3.4: 13.8$ \\
PET with green & $55.8: 4.3: 27.8$ & $60.4: 4.1: 26.0$ & $59.9: 5.1: 26.1$ & $62.1: 4.9: 25.3$ & $65.0: 5.3: 24.9$ & $64.9: 5.7: 23.2$ & $65.6: 5.7: 23.4$ \\
PET with PEN & $56.2: 4.0: 27.9$ & $57.1: 3.8: 25.8$ & $61.8: 4.3: 27.4$ & $60.6: 4.7: 24.7$ & $59.7: 5.8: 23.9$ & $62.5: 5.2: 23.1$ & $63.9: 6.2: 22.1$ \\
Can & $54.6: 3.9: 28.1$ & $54.9: 4.1: 26.8$ & $55.6: 3.9: 27.4$ & $57.0: 4.4: 27.1$ & $57.2: 4.6: 27.2$ & $56.6: 4.9: 27.8$ & $58.3: 4.7: 27.0$ \\
\hline
\end{tabular}

${ }^{1)}$ peak area ratio of alpha-fenchene, camphor, and endobornyl acetate peak. 


\section{ACKNOWLEDGEMENTS}

I would like to express my sincere appreciation to Mr. Kim Seok-Ju, Song Sang-Hoon and Mrs. Moon SooHyoun in CJ Food Company for their kind guidance for using G.C. and M.S.

\section{REFERENCES}

1. Yuko I, Hideki T, Nobuko K, Katsumi K. 1997. Change of lemon flavor components in an aqueous solution during UV irradiation. J Agric Food Chem 45: 463-466.

2. Chan HWS. 1977. Photo-sensitized oxidation of unsaturated fatty acid methyl esters.: The identification of different pathways. J Am Chem Soc March: 100-104.

3. Kim BH, Park YA. 1994. Comparative study on the mutagenic activity of phenothiazines by UV-A irradiations. $J$ Food Hygiene and Safety 9: 15-21.

4. Elmer D. 1982. Vitamins in pharmaceutical formulations. J Pharm Sci 71: 1073-1096.

5. Liu X, Macaulay EDM, Pickett JA. 1984. Propheromones that release pheromonal carbonyl compounds in light. $J$ Chem Ecol 10: 809-822.

6. Ma X, Gang DR. 2006. Metabolic profiling of turmeric (Curcuma longa L.) plants derived from in vitro micropropagation and conventional greenhouse cultivation. $J$ Agric Food Chem 54: 9573-9583.

7. Characteristics and application of PEN film. 1996. The Packaging News 4: 64-73.

8. Kim KO, Lee YC. 1985. Food color. In Sensory Evaluation of Food. HakYeon Publishing Inc., Seoul,
Korea. Ch 5: 74-90.

9. Brody AL. 1989. Flavor interacts with packaging. Prepared Foods 9: 128-132.

10. Mattheis JP, Buchanan DA, Fellman J. 1997. Volatile constituents of bing sweet cherry fruit following controlled atmosphere storage. J Agric Food Chem 45: 212-216.

11. Schieberle P, Grosch W. 1989. Potent odorants resulting from the peroxidation of lemon oil. Z Lebensm Unters Forsch 189: 26-31.

12. Rapior S, Breheret S, Talou T, Bessiere JM. 1997. Volatile flavor constituents of fresh Marasmius alliaceus (garlic Marasmius). J Agric Food Chem 45: 820-825.

13. Zheng Y, Brown S, Ledig WO, Mussinan C, Ho CT. 1997. Formation of sulfide-containing flavor compounds from reactions of furaneol and cystein, glutathione, hydrogen sulfide, and alanine/hydrogen sulfide. J Agric Food Chem 45: 894-897.

14. Harborne JB, Baxter H. 1985. Phytochemical dictionary, A Handbook of Bioactive Compounds from Plants. Taylor \& Francis Inc., New York, USA. p 557.

15. Arctander S. 1969. Perfume and Flavor chemicals I. Det Hoffensbergske Etablissment Co., Munchen, Deutschland. p 53, 565, 1384, 2283.

16. Furia T, Bellanca N. 1970. Fenaroli's Handbook of Flavor Ingredients. 2nd ed. CRC Press, p 57, 202, 421.

17. Youko S, Kikue K, Akio K. 1987. Characteristic flavor components in the brew of cooked clam and the effect of storage in flavor formation. J Agric Food Chem 45: 894-897.

18. Meilgaard MS, Peppard TL. 1986. The flavour of beverages. In Food Flavours Part B. Morton ID, MacLeod AJ, eds. Elsevier, Amsterdam, Netherlands. p 99-170.

(Received September 3, 2009; Accepted October 21, 2009) 